\title{
INOVAÇÃO EM FOCO: O REPENSAR DA MATRIZ CURRICULAR DO CURSO SUPERIOR DE TECNOLOGIA EM GESTÃO COMERCIAL
}

\author{
MARINGÁ/PR MAIO/2018
}

\author{
Fernando Alberto Jorgeto - Unicesumar - fernandojorgeto@gmail.com \\ Ednar Rafaela Mieko Shimohigashi - Unicesumar - miekoead@gmail.com \\ Victor Vinicius Biazon - Unicesumar - victorbiazon@gmail.com \\ Eliane Zanoni - Unicesumar - elianezanoni@gmail.com \\ Wainer Cristiano Cancian - Unicesumar - wainercristian@gmail.com \\ Simone Oliveira dos Santos Cardoso - Unicesumar-admsimonecardoso@gmail.com \\ Renata Ramos Pavan Terra - Unicesumar - renata.terra@unicesumar.edu.br
}

Tipo: Investigação Científica (IC)

Natureza: Relatório Final de Pesquisa

Categoria: Conteúdos e Habilidades

Setor Educacional: EDUCAÇÃO SUPERIOR

\begin{abstract}
RESUMO
Pensar a estrutura de conteúdos de um curso superior de tecnologia vai muito além de realizar o planejamento distribuindo as disciplinas ao longo dos períodos do curso. Para que a educação de qualidade realmente seja alcançada e seus egressos possuam o perfil exigido, tanto àquelas exigidas pelo mercado de trabalho quanto às características técnicas, científicas e humanas, é necessário pensar de forma crítica sobre o currículo oferecido pelas IES. Baseados nesse entendimento e utilizando-se de um recorte, o presente estudo tem como objetivo analisar os impactos causados nos índices de aprovação dos alunos após alteração da matriz curricular no curso superior de tecnologia em Gestão Comercial, de um centro universitário brasileiro. A análise focou disciplinas que pertenciam ao primeiro ano do curso e que foram alteradas para o segundo ano, e vice-versa. Os resultados mostraram que apesar das disciplinas que eram do segundo ano do curso e que passaram para 0 primeiro ano terem sofrido quedas nos índices de aprovação, de forma geral a mudança apresentou melhores índices de aprovação dos alunos, quando comparados com disciplinas que eram oferecidas no mesmo período do curso na matriz antiga. Para melhores conclusões a respeito deste estudo, outros cursos que tenham sofrido alterações em sua matriz curricular podem realizar comparações, além de abordar sobre a importância de se pensar a matriz curricular vigente com olhar distinto.
\end{abstract}

Palavras-chave: currículo; mudança; aprovação 


\section{1 - INTRODUÇÃO}

Pensar mudanças nos cursos superiores de tecnologia permite alinhar o perfil do egresso às expectativas do mercado e às exigências da legislação vigente. Assim, a proposta de mudança da matriz curricular do curso superior de tecnologia em Gestão Comercial, modalidade a distância, de um centro universitário brasileiro, vem ao encontro do alinhamento às mudanças no perfil do egresso publicadas no Catálogo Nacional dos Cursos Superiores de Tecnologia e alinhada às diretrizes informadas nos últimos anos pelo INEP (Instituto de Pesquisas Educacionais Anísio Teixeira) para o Enade (Exame Nacional do Desempenho dos Estudantes).

Apesar da matriz curricular anterior contemplar os conteúdos requeridos para o exercício da profissão do gestor comercial e o curso ter alcançado bons índices nas últimas avaliações oficiais, buscou-se adaptar o conteúdo das disciplinas, promovendo alteração de períodos ou integração/dispersão de conteúdos de modo a tornar melhor a compreensão do aluno, conforme sua maturidade no curso e mais atrativo a evolução dos eixos temáticos ao longo do curso. A preocupação também direcionou-se no sentido de melhorar os índices de aprovações em algumas disciplinas que se apresentavam desvelos.

O presente trabalho tem como proposta destacar as adequações que ocorreram na matriz curricular e analisar seu impacto no curso analisado, no que se refere ao índice de aprovação nas disciplinas. A análise está estruturada por meio de dados expressos pela porcentagem de aprovação, comparando-se os anos de 2015, quando o curso trabalhava somente com a matriz antiga, e 2017, quando a matriz nova já estava em pleno funcionamento.

A organização deste estudo inicia com uma pequena abordagem sobre a legislação que envolve o ensino brasileiro, em seguida destaca brevemente a teoria dos currículos e por fim apresenta a análise dos dados e as conclusões obtidas com o estudo.

\section{2 - APRESENTAÇÃO DO CURSO SUPERIOR EM GESTÃO COMERCIAL}

A educação superior compõe um dos níveis da educação formal brasileira, sendo regulamentada, entre outros, pela lei 9.394 de 20 de dezembro de 1996 conhecida como LDB - Lei das Diretrizes e Bases da Educação Nacional - (BRASIL, 1996). Em consonância com as Diretrizes Curriculares Nacionais, direcionada à Educação 
Profissional de Nível Tecnológico (PARECER CNE/CP: 29/2002), o MEC - Ministério da Educação - apresenta uma proposta em que os CST - Cursos Superiores de Tecnologia - vêm como resposta do setor educacional às necessidades e demandas da sociedade brasileira. Espera-se que o CST capacite o estudante para o desenvolvimento de competências profissionais traduzidas na aplicação, desenvolvimento e difusão de tecnologias e ainda na gestão de processos de produção de bens e serviços procurando criar condições para articular, mobilizar e colocar em ação suas competências com eficiência e eficácia, aos desafios e requerimentos do mundo do trabalho.

As diretrizes do CST em Gestão Comercial na IES pesquisada, constam publicadas no Catálogo Nacional de Cursos Superiores de Tecnologia, em que apresenta o perfil profissional do egresso, o que significa que a oferta das disciplinas nos módulos deve ser capaz de munir os alunos das competências necessárias para que, ao final do curso, corresponda ao que se espera deste profissional. A tabela 1 apresenta as principais características do curso e o perfil do egresso:

Tabela 1 - Diretrizes (perfil do egresso) do curso de Gestão Comercial

\begin{tabular}{|c|c|c|c|}
\hline Ano & Perfil profissional de conclusão & $\begin{array}{l}\text { Horas } \\
\text { mínimas }\end{array}$ & Campo de atuação \\
\hline $\begin{array}{r}2006- \\
2010\end{array}$ & 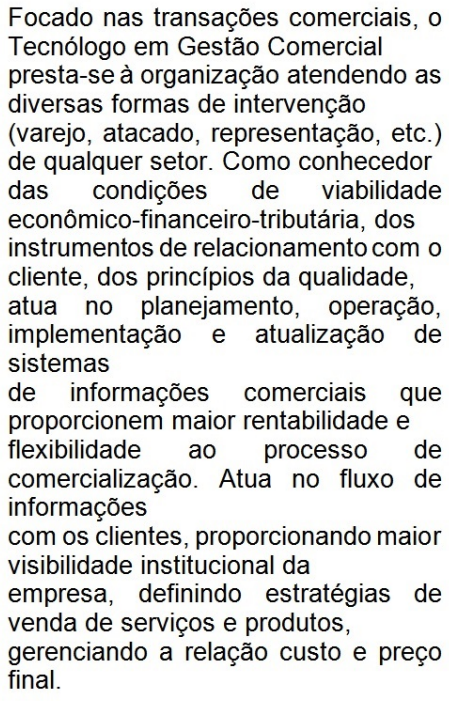 & 1600 & não consta \\
\hline 2016 & $\begin{array}{l}\text { Articula e decide sobre as vendas em } \\
\text { negócios diversos. Realiza estudos de } \\
\text { viabilidade econômica, financeira e } \\
\text { tributária. Elabora análises comerciais } \\
\text { considerando as demandas e } \\
\text { oportunidades do mercado. Planeja } \\
\text { pesquisas de mercado. Desenvolve } \\
\text { relacionamentos pós-venda com } \\
\text { clientes. Gerencia sistemas de } \\
\text { informações comerciais. Define } \\
\text { métodos de formação de preços, } \\
\text { considerando aspectos tributários, de } \\
\text { custos, da concorrência e do valor } \\
\text { para o cliente. Gerencia a área } \\
\text { comercial de uma organização. Avalia } \\
\text { e emite parecer técnico em sua área } \\
\text { de formação. }\end{array}$ & 1600 & $\begin{array}{l}\text { Empresas varejistas, atacadistas } \\
\text { e de representação comercial. } \\
\text { Empresas de beneficiamento de } \\
\text { bens de consumo e industriais. } \\
\text { Empresas prestadoras de } \\
\text { serviços de consumo final. } \\
\text { Empresas que atuam na } \\
\text { comercialização de insumos nos } \\
\text { setores de agricultura, pecuária, } \\
\text { pesca, extrativismo }\end{array}$ \\
\hline
\end{tabular}


Fonte: Catálogo Nacional de Cursos superiores de Tecnologia - Ministério da Educação $(2006 ; 2010 ; 2016)$

Realizada a abordagem prevista sobre a legislação que envolve o ensino brasileiro, destacar-se-á brevemente sobre os currículos para posterior apresentação dos dados da análise da reorganização da matriz curricular.

\section{3 - O CURRÍCULO PARA OS CURSOS SUPERIORES DE TECNOLOGIA}

Por meio da Resolução no 3 de 18 de dezembro de 2002, o Ministério da Educação, expõe que nos Referenciais Curriculares Nacionais para a Educação Profissional de Nível Técnico consta o "paradigma da educação profissional, com o qual se deve trabalhar e que deve posicionar os currículos escolares tanto dos cursos técnicos quanto dos cursos superiores de tecnologia" (MEC, 2002. p. 15). A articulação dos saberes com as situações-meio é reflexo da relação entre o (1) doutrinário e o teórico e o (2) técnico e o prático, DNA dos cursos superiores de tecnologia. Do ponto de vista curricular, seria a aproximação da teoria com a prática, estimulando o pensamento crítico e criativo, além de forte impulso para a perspectiva interdisciplinar.

A luz desta reflexão, buscou-se o pensar sobre a matriz curricular do CST em Gestão Comercial pesquisado e medir os impactos que tais mudanças ocasionam. Afinal, estamos trabalhando com sonhos e repensar as experiências do aluno com vistas à melhoria qualitativa é nossa obrigação enquanto educadores.

\section{4 - PROCEDIMENTOS METODOLÓGICOS}

Segundo seus fins, a pesquisa é um estudo descritivo que busca especificar as características e o perfil de um grupo de pessoas, que se pretende mediar e/ou coletar informações de maneira conjunta sobre variáveis que se relacionam (SAMPIERI, COLLADO, LUCIO, 2013).

Segundo a natureza, Sampieri, Collado e Lucio (2013) a pesquisa possui enfoque quantitativo, baseado na medição numérica e na análise estatística para estabelecer padrão e comprovar teoria, expressos pela porcentagem de aprovação dos acadêmicos, comparando-se os anos de 2015 e 2017 de acordo com as adequações que 
aconteceram na matriz curricular.

Segundo as estratégias, o estudo caracteriza-se como documental, que são relatórios para análise do fenômeno, e pesquisa bibliográfica, para relação ao conteúdo da pesquisa, como artigos científicos e legislação (SANTOS, 2005).

\section{5 - APRESENTAÇÃO E DISCUSSÃO DOS RESULTADOS}

Este estudo tem como objeto analisar as consequências da alteração de matriz curricular do CST em gestão comercial em uma IES do sul do Brasil, em especial para este estudo, relacionados aos números de aprovações em cada uma das matrizes. $O$ curso analisado está estruturado em oito módulos, ao longo de dois anos, sendo que cada módulo representa um eixo temático. A matriz curricular traz dezoito disciplinas obrigatórias, com a carga horária de cem horas, sendo duas destas de formação geral para todos os cursos, que acontecem nos módulos 5 e 6 e que não foram destacadas nas figuras abaixo para melhor representação, totalizando 1.800 horas somando-se $6 \%$ desse total de horas destinadas à atividades acadêmicas complementares.

O ajuste da matriz curricular, alterando o período de algumas disciplinas, objetivava desenvolver o conhecimento dos alunos aos conteúdos relacionados entre si, considerando seu nível de maturidade para que pudesse focar seus esforços e ao mesmo tempo tivesse subsídios para o desenvolvimento de conteúdos com maior complexidade. Apesar da matriz curricular ter sua implantação iniciada em 2016, o foco de análise se concentrou nas disciplinas que mudaram do primeiro ano para o segundo ano e vice-versa a partir de 2017, quando o curso já possuía o primeiro e o segundo ano do curso implantados. A seguir, são apresentadas as duas matrizes curriculares, dos anos de 2015 e 2017, com destaque para as alterações mencionadas em cada uma delas:

Figura 01: Matriz curricular (2015) 


\begin{tabular}{|c|c|c|c|}
\hline \multirow{2}{*}{\multicolumn{2}{|c|}{$\frac{1{ }^{\circ} \text { ANO }}{\text { Eixo temático: Administração Empreendedora }}$}} & \multicolumn{2}{|r|}{$2^{\circ} \mathrm{ANO}$} \\
\hline & & \multicolumn{2}{|r|}{ Eixo temático: Planejamento na gestão de vendas } \\
\hline 1 & Empreendedorismo & 5 & Logística e centros de distribuição \\
\hline \multicolumn{2}{|r|}{$\begin{array}{l}\text { Eixo temático: Estratégias com foco nos } \\
\text { consumidores }\end{array}$} & \multicolumn{2}{|r|}{$\begin{array}{l}\text { Eixo temático: Pessoas como vantagem } \\
\text { competitiva }\end{array}$} \\
\hline 2 & Comportamento do consumidor & 6 & Comunicação empresarial e negociação \\
\hline \multicolumn{2}{|r|}{ Eixo temático: Noções de gestão empresarial } & \multicolumn{2}{|r|}{$\begin{array}{c}\text { Eixo temático: Especificidades e serviços em } \\
\text { vendas }\end{array}$} \\
\hline \multirow{2}{*}{3} & Conceitos da administração e ética empresarial & \multirow{2}{*}{7} & Vendas de serviços \\
\hline & Economia e sociedade & & Especificidades do varejo \\
\hline \multicolumn{2}{|r|}{$\begin{array}{l}\text { Eixo temático: Responsabilidade e sustentabilidade } \\
\text { em vendas }\end{array}$} & \multicolumn{2}{|r|}{ Eixo temático: Novos negócios e regulamentação } \\
\hline
\end{tabular}

Fonte: Projeto pedagógico do curso de Gestão Comercial, 2015.

Figura 02: Matriz curricular (2017)

\begin{tabular}{|c|c|c|c|}
\hline \multirow{2}{*}{\multicolumn{2}{|c|}{$\begin{array}{c}1^{\circ} \mathrm{ANO} \\
\text { Eixo temático: Administração empreendedora }\end{array}$}} & \multicolumn{2}{|r|}{$2^{\circ}$ ANO } \\
\hline & & \multicolumn{2}{|r|}{ Eixo temático: Planejamento de novos negócios } \\
\hline \multirow{2}{*}{1} & Empreendedorismo & \multirow{2}{*}{5} & Logística e centros de distribuição \\
\hline & Conceitos da administração e ética empresarial & & Negócios Eletrônicos \\
\hline \multicolumn{2}{|r|}{$\begin{array}{c}\text { Eixo temático: Pessoas como vantagem } \\
\text { competitiva }\end{array}$} & \multicolumn{2}{|r|}{$\begin{array}{c}\text { Eixo temático: Noções de economia e oferta de } \\
\text { serviços }\end{array}$} \\
\hline \multirow[t]{2}{*}{2} & $\begin{array}{l}\text { Gestão de pessoas e desenvolvimento de } \\
\text { equipes }\end{array}$ & \multirow[t]{2}{*}{6} & Vendas de serviços \\
\hline & Comunicação empresarial e negociação & & Economia e Sociedade \\
\hline \multicolumn{2}{|r|}{ Eixo temático: Estratégias no varejo } & \multicolumn{2}{|r|}{ Eixo temático: Gestão contábil e financeira } \\
\hline \multirow{2}{*}{3} & Estratégias e promoção de vendas & \multirow[b]{2}{*}{7} & Noções de gestão financeira \\
\hline & Especificidades do varejo & & Contabilidade gerencial \\
\hline \multicolumn{2}{|r|}{ Eixo temático: Gestão mercadológica } & \multicolumn{2}{|r|}{ Eixo temático: Regulamentação e vendas } \\
\hline \multirow{2}{*}{4} & Fundamentos de marketing & \multirow[b]{2}{*}{8} & Gestão de vendas \\
\hline & Comportamento do consumidor & & Direito do consumidor e comercial \\
\hline
\end{tabular}

Fonte: Projeto pedagógico do curso de Gestão Comercial, 2017.

A análise foi realizada com base no índice de aprovações das disciplinas, pois de acordo com o índice de aprovação pudemos analisar o desempenho do aluno ao longo do eixo temático. Foram realizadas o cruzamento de três análises de dados:

1. Análise por disciplina: comparativo de aprovação entre as disciplinas que sofreram alteração de ano curricular (2015 e 2017).

2. Análise por módulo: comparação do nível de aprovação entre o módulo em que a disciplina era ofertada em 2015 com a disciplina que a substituiu em 2017.

3. Análise por módulo: comparação do nível de aprovação entre o módulo em que a disciplina passou a ser ofertada em 2017 com o módulo em que a disciplina era ofertada em 2015.

As análises dos itens 2 e 3 se justificam para verificar se a variação do índice de aprovação ocorreu em função da troca do módulo de oferta da disciplina ou se é uma 
característica do período do curso.

A primeira disciplina analisada foi Economia e Sociedade que em 2015 fazia parte do módulo 3 ( $1^{\circ}$ ano) e em 2017 passou a ser ofertada no módulo 6 ( $2^{\circ}$ ano). Realizando a análise oํ 1, em 2015, o índice de aprovação da disciplina estava em 41\%. Com sua mudança, no ano de 2017, o índice saltou para 75\% de aprovação, ou seja, um aumento de $34 \%$ ao passar a disciplina para o segundo ano. Realizando a análise $n-2$, quando a disciplina de Economia e Sociedade passou a ser ofertada no módulo 6 (2017), ela deixou de ser ofertada no módulo 3 (2015). Por sua vez, no módulo 6 de 2015 acontecia Administração de Conflitos e Relacionamentos que apresentava um índice de aprovação de $82 \%$, ou seja, houve uma queda de $7 \%$ se comparado com a disciplina de Economia e Sociedade que passou a ser ofertada em seu lugar. Contudo, realizando a análise oㅜ 3, no módulo 3 de 2017, passou a ser ofertada a disciplina de Especificidades do Varejo com um índice de aprovação de $50 \%$, ou seja, aumento de $9 \%$ dos alunos aprovados.

Figura 03: Exemplo do cruzamento das três análises realizadas nas matrizes de 2015 e 2017

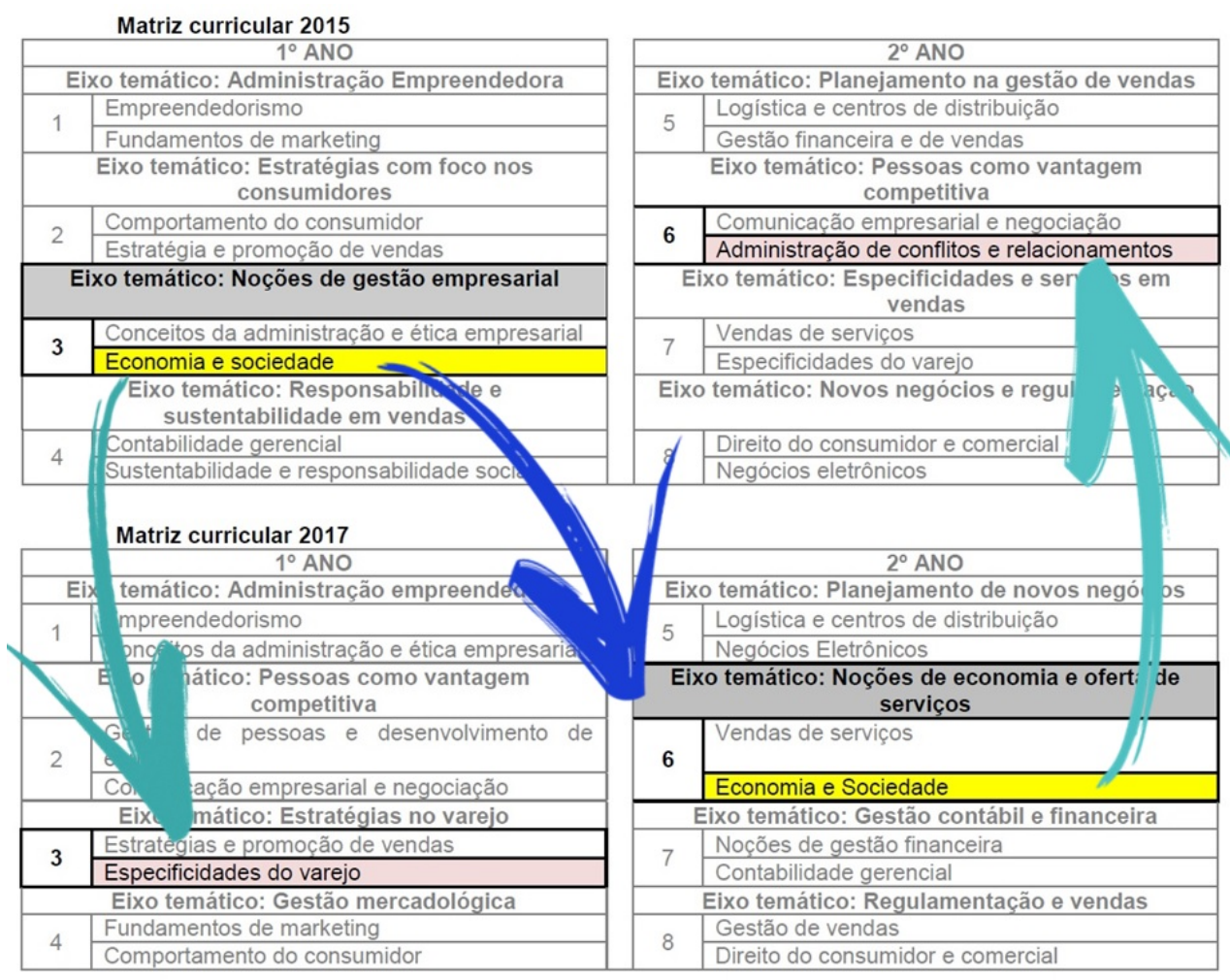

Fonte: Elaborado pelos autores

A segunda disciplina analisada foi Contabilidade Gerencial, considerada desvelos pelos índices de aprovações que vinham sendo apresentados. Em 2015 ela era ofertada no 
módulo 4 ( $1^{\circ}$ ano) e em 2017 passou a ser ofertada no módulo 7 ( $2^{\circ}$ ano). Realizando a análise no 1, em 2015, o índice de aprovação na disciplina estava em 33\% dos alunos. Com a mudança, no ano de 2017 , o índice saltou para $61 \%$ de aprovados, um aumento de $28 \%$. Realizando a análise oㅡ 2, quando Contabilidade Gerencial passou a ser ofertada no módulo 7 (2017), ela deixou de ser ofertada no módulo 4 (2015). Por sua vez, no módulo 7 de 2015, acontecia Especificidades do Varejo que apresentava um índice de 63\% de aprovação, ou seja, em 2017 houve uma ligeira queda de $2 \%$ no número de aprovados. Realizando a análise n 3, no módulo 4 de 2017 passou a ser ofertada Comportamento do Consumidor com índice de aprovação de 42\%, aumento de 9\% no índice de aprovados.

A terceira disciplina analisada foi Comunicação Empresarial e Negociação, ofertada em 2015 no módulo 6 ( $2^{\circ}$ ano) e em 2017 no módulo 2 ( $1^{\circ}$ ano). Realizando a análise № 1 , em 2015, o índice de aprovados estava em 78\% e em 2017 o índice foi para 62\%, uma queda de $16 \%$ de aprovações. Realizando a análise $\mathrm{n}^{\circ}=2$, quando Comunicação Empresarial e Negociação passou a ser ofertada no módulo 2 (2017), ela deixou de ser ofertada no módulo 6 (2015). Por sua vez, no módulo 2 de 2015 acontecia Comportamento do Consumidor com índice de aprovação em $60 \%$, ou seja, queda de $2 \%$ nas aprovações. Realizando a análise n 3, no módulo 6 de 2017, passou a ser ofertada a disciplina Vendas de Serviços apresentando $79 \%$ de aprovação e os índices permaneceram praticamente estáveis, com um aumento de apenas $1 \%$.

Por fim, a quarta disciplina analisada foi Especificidades do Varejo que era ofertada no módulo 7 ( $2^{\circ}$ ano) e passou a ser ofertada no módulo 3 ( $1^{\circ}$ ano). Realizando a análise $\mathrm{n}^{\circ}$ 1, em 2015, o índice de aprovação era de 63\% dos alunos e em 2017 o índice foi de $50 \%$, ou seja, uma queda de $13 \%$ no número dos aprovados. Realizando a análise ํㅡ 2 , quando a disciplina de Especificidades do Varejo passou a ser ofertada no módulo 3 (2017), ela deixou de ser ofertada no módulo 7 (2015). Por sua vez, no módulo 3 de 2015 acontecia Economia e Sociedade que apresentava um índice de aprovação de $41 \%$, aumentando em $9 \%$ no índice de alunos aprovados. Realizando a análise $n^{\circ}$ 3, no módulo 7 de 2017 passou a ser ofertada a disciplina Noções de Gestão Financeira, representando $77 \%$ de aprovados e um aumento de 14\% nas aprovações.

\section{6 - CONSIDERAÇÕES FINAIS}

$\mathrm{Na}$ análise realizada, buscou-se evidenciar os desafios e as consequências ocorridas com esta troca, além de verificar a hipótese de que a matriz nova se tornou mais atrativa 
para os alunos, à medida em que os índices de aprovações foram alterados. Superficialmente, houve aumentos e quedas nos índices de aprovações, mas ao aprofundar a análise é possível considerar o saldo positivo desta mudança de matriz.

Em geral, percebe-se que os índices de aprovações são maiores no segundo ano do curso, provavelmente devido ao conhecimento do aluno em relação aos eixos temáticos anteriores. Mesmo com algumas quedas nos índices de aprovações quando as disciplinas do segundo ano do curso em 2015 foram transferidas para o primeiro ano em 2017, ainda se percebe um ganho em relação ao envolvimento do aluno com os conteúdos do curso, pois na comparação com as disciplinas que aconteciam no mesmo período em 2015, em 2017 houve aumento, ainda que pequeno, nos índices de aprovação do primeiro ano do curso.

Repensar a matriz curricular, se mostrou eficaz, sobretudo no agrupamento das disciplinas que exigem conhecimentos matemáticos como Contabilidade Gerencial e Noções de Gestão Financeira, consideradas desvelos pelos índices de aprovações apresentados em 2015 e que obtiveram ótimos resultados no ano de 2017 com 61\% e $77 \%$ de aprovação, respectivamente.

Estas análises podem auxiliar outros gestores educacionais, considerando o impacto que essa mudança traz sobre o desenvolvimento dos alunos nas disciplinas. Também é possível auxiliar os demais gestores a repensarem a matriz de conteúdos do seu curso, sobretudo em disciplinas consideradas críticas, para melhor se ajustarem ao desenvolvimento do aluno durante o curso, trabalhando assuntos de maior complexidade, concentrando o mesmo campo de conhecimento em um mesmo eixo e aprimorar o perfil do egresso de acordo com as avaliações oficiais. Para aprofundar os conhecimentos trazidos pelo estudo, pode-se realizar a análise sob a ótica de outros cursos que experimentaram mudanças em suas matrizes curriculares.

\section{REFERÊNCIAS}

BRASIL, LEI № 9.394, DE 20 DE DEZEMBRO DE 1996. Presidência da República: Casa Civil. Disponível em < http://www.planalto.gov.br/ccivil_03/leis/L9394.htm> Acesso em: 16 abr 2018.

BRASIL, PARECER CNE/CES № 436/2001. Disponível em > Acesso em: 16 abr 2018. 
FRAUCHES, Celso da Costa. LDB anotada e legislação complementar: Lei oㅡ. 9.394 de 20 de dezembro de 1996. Marília: CM, 2000.

MEC - MINISTÉRIO DA EDUCAÇÃO CONSELHO NACIONAL DE EDUCAÇÃO. Resolução no 3 de 18 de dezembro de 2002. PARECER CNE/CP: 29/2002. Disponível em Acesso em: 16 abr 2018.

SAMPIERI, Roberto Hernández; COLLADO, Carlos Fernández; LUCIO, María del Pilar Baptista. Metodologia de pesquisa. 5 ed. Porto Alegre: Penso, 2013.

SANTOS, Izequias Estevam dos. Manual de métodos e técnicas de pesquisa científica. 5 ed. Niterói-Rj: Impetus, 2005. 